
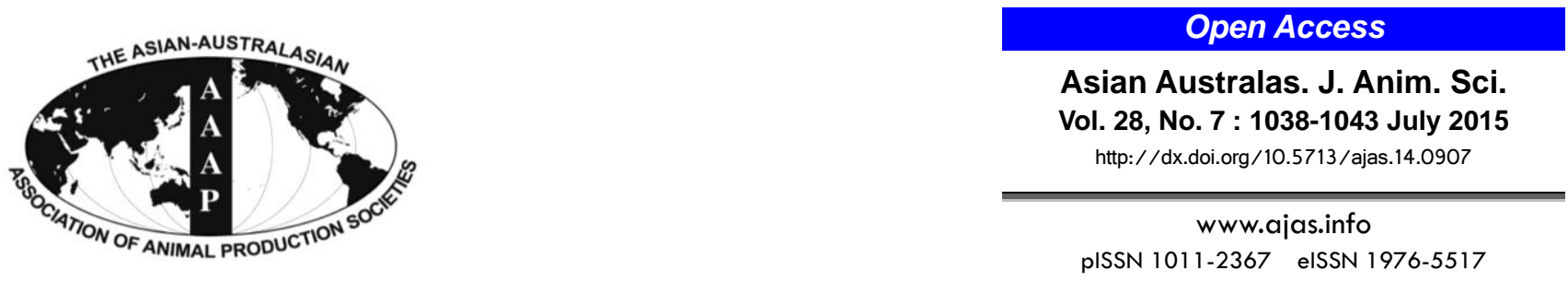

\title{
Effects of Mixing on the Aggressive Behavior of Commercially Housed Pigs
}

\author{
Shin-Jae Rhim*, Seung-Hun Son, Hyun-Su Hwang, Jae-Kang Lee, and Joon-Ki Hong ${ }^{1}$ \\ School of Bioresource and Bioscience, Chung-Ang University, Ansung 456-756, Korea
}

\begin{abstract}
In this study, we investigated the effects of mixing on the aggressive behavior of commercially housed pigs. The behavioral patterns of 36 groups of pigs (a total of 360 animals) were observed over 3 consecutive days directly after weaning ( $25 \pm 1.2$ days of age), and 25 and 50 days later with the aid of video technology. Fight latency and total duration and frequency of fighting were significantly different among the age groups. The aggressive behaviors decreased in 75-day old pigs if compared to 25- and 50-day old animals. Moreover, dominance index (DI) was higher in 25-day old and lower in 75-day old pigs. A comparison of dominant (DI $>0$ ) and submissive $(\mathrm{DI}<0)$ pigs showed significant differences $(\mathrm{p}<0.05)$ for major aggressive behaviors in all age groups. Dominant pigs were involved in more aggressive interactions, had longer fights, and initiated more fights than submissive pigs. Post-mixing aggressive behavior was altered by previous experience of mixing. Aggressive behavior and DI are suitable methods for analyzing the effects of mixing on commercially housed growing pigs. (Key Words: Aggressive Behavior, Dominance Index, Interaction, Mixing, Pig)
\end{abstract}

\section{INTRODUCTION}

Most farm animals have the tendency to form groups. Living in groups has associated cost and benefits (Estevez et al., 2007). In a group, individuals have more time to rest and forage, and most importantly lower predation risk. Synchronization of nursing, feeding, and resting is also a risk-reducing strategy (Ewbank, 1972; Wechsler and Brodmann, 1996; Krause and Ruxton, 2002). The cost of group living refer to competition for food and space. These limited resources may trigger social stress and aggression (Mendl et al., 1992; Rhim, 2014). The consequences of aggression are mainly studied because they are important for the health and welfare of farm animals (Ewbank and Bryant, 1972).

In the social structure of the wild boar Sus scrofa, a clear and stable hierarchy exists among group members with low frequency of threats and aggression (McGlone,

\footnotetext{
* Corresponding Author: Shin-Jae Rhim. Tel: +82-31-670-4842, Fax: +82-31-676-4842, E-mail: sjrhim@ @au.ac.kr

${ }^{1}$ Swine Science Division, National Institute of Animal Science, Cheonan 331-801, Korea.

Submitted Dec. 1, 2014; Revised Feb. 3, 2015; Accepted Feb. 10, 2015
}

1986). Under commercial conditions, the groups comprise animals of similar age and body mass, which are penned at high density without dominant adult animals. These groups show a wide range of individual behaviors in response to variously challenging situations (van Erp-van der Kooji et al., 2002). Mixing is a common practice in modern swine husbandry and it causes intensive aggression in commercial housing systems for pigs.

Aggressive behavior can be easily observed when unknown pigs are mixed into a group. The major factor causing the aggression is unfamiliarity. Post-mixing fighting occurs between pigs that are unfamiliar with each other, and sometimes leads to serious injury (Meese and Ewbank, 1972; Pitts et al., 2000). For the establishment of social hierarchy, aggression may occur (Zayan and Dantzer, 1990). Moreover, the aggression that occurs by mixing results in physiological stress responses (Arey and Edward, 1998); for this reason, most researchers agree that mixing should be avoided (Erhard et al., 1997).

Problems associated to aggressive post-mixing aggressive behavior include reduced body mass and poor meat quality (Stookey and Gonyou, 1994). These results in commercial swine production are known as a significant cost to economic consequences and serious animal welfare 
issue (Ayo et al., 1998; O'Connell and Beattie, 1999). However, the effect of group housing on the behavior and welfare of pigs have not been well documented (Hillmann et al., 2003; Rhim, 2012). The social stability of a group is facilitated by gradual and infrequent integration of new members to the group (Turner et al., 2006). In contrast, most commercial pigs are continuously exposed to sudden mixing events with unrelated animals in environment that limits dispersal and display of suitable submissive behavior (Erhard et al., 1997). Unfortunately, regrouping is still a common procedure in swine husbandry.

The degree of aggression depends on several conditions such as body mass, space, group size, and degree of familiarity (Meese and Ewbank, 1973; Algers et al., 1990; Hoy and Bauer, 2005; stukenborg et al., 2011). However, it is unclear how external and intrinsic factors interact and whether previous mixing experience affects the aggressive behavior of pigs. The effects of rearing conditions on the behavior of pigs are poorly understood (Schouten, 1991; van de Weerd et al., 2005). Therefore, the aggressive behavior of commercially housed pigs has received much attention.

There is little evidence of an optimum mixing time to minimize aggressive behavior of pigs. We used a new approach for the study of aggressive behavior caused by social mixing that occurs on commercial farms. The aim of this study was to compare the aggressive behaviors of commercially housed pigs when mixed at different times after weaning.

\section{MATERIALS AND METHODS}

Data were collected on a commercial swine farm located in Ansung, Gyeonggi Province, Korea form April 2007 through February 2009. Protocols for this experiment followed the guidelines by the National Research Council (1996). A total of 360 weaned pigs (YorkshirexLandrace) were used in this experiment. The sex ratio was $1: 1$. The environmental control systems were the same among all housing facilities in this study. In each room, the temperature was controlled by ventilation fans and heaters and was maintained at $20 \pm 2^{\circ} \mathrm{C}$. Pigs were fed ad libitum, water was constantly accessible through nipple drinkers.

For the behavioral observations, piglets were weaned at $25( \pm 1.2)$ days of age. Immediately after weaning, 10 piglets were randomly chosen, marked on their backs, and mixed for 25 days in a $6.0 \mathrm{~m} \times 6.0 \mathrm{~m}$ pen with solid concrete flooring and a heat lamp. Two video cameras were installed on the ceiling at the opposing corners, so that the pen could be observed from 2 directions. The recording of the weaned pigs was conducted for 10 hours per day during 3 consecutive days. The second and third observations were carried out at 50 and 75 days of age. Prior to second and third observations, the same pigs that had already been mixed at weaning (day 25) were randomly re-marked and re-mixed. The mixed pigs were reared in each pen for 25 days until next session. After mixing, the pigs were videotaped for 3 consecutive days.

All behavioral data were obtained from the videotapes. Behaviors were analyzed from images digitally recorded from 08:00 $\mathrm{h}$ to $18: 00 \mathrm{~h}$ on days 25,50 , and 75 (day $0=$ birth day). Video tapes were analyzed using a video recorder with jog-shuttle function. Instantaneous scan sampling was carried out at 2-min intervals. All video recordings were viewed by one trained observer who was blinded to the treatment to eliminate subjective bias and inter-individual discrepancy (Li and Wang, 2011).

The following behaviors were recorded: inactivity, chewing on other animals, locomotion, pen exploration, drinking, feeding, elimination, tail biting, belly nosing, fighting, other social interactions, and other behaviors (Table 1). Moreover, all aggressive interactions were registered by recording the time of occurrence. Aggressive behavior was defined as follows: interaction between two pigs involving physical contact (biting, knocking, or lateral fighting with the opponents standing in antiparallel position

Table 1. Ethogram of behavioral categories and their respective definitions (adapted from Statham et al., 2011; Rhim, 2012)

\begin{tabular}{|c|c|}
\hline Behavior & Description \\
\hline Inactive & Motionless and sleeping \\
\hline Chewing & Chewing (not on another pig) with its head raised and away from the feeder \\
\hline Locomotion & Any movement including walking, running, scampering, and rolling \\
\hline Pen exploration & Sniffing, touching, sucking or chewing any object that is part of the pen \\
\hline Drinking & Drinking water or manipulating the drinker with or without ingestion of water \\
\hline Feeding & Head positioned in the feeder or chewing food displaced from the feeder \\
\hline Excretion & Defecating or urinating \\
\hline Tail biting & Having the tail of another pig in its mouth and biting or pulling hard enough to cause a reaction in the other pig \\
\hline Belly nosing & Repeated thrusting of snout into the belly of another pig \\
\hline Fighting & Head-thrusting, ramming, biting, or pushing another pig \\
\hline Other social & All other social interactions including mounting, head rubbing, and nosing parts of the body other than the belly \\
\hline Other & All other behaviors not listed above \\
\hline
\end{tabular}


both performing bites or knocks) starting with the first physical contact and ending with submissive behavior (escape) shown by one of the opponents or when both pigs moved away from each other (Langbein and Puppe, 2004; Borberg and Hoy, 2009; Krauss and Hoy, 2011; Rhim, 2012).

In particular, fighting behavior within aggressive interactions was monitored. Fighting began when a pig bit another pig and the fight lasted for more than $1 \mathrm{~s}$, and terminated when the pigs were aparat for $5 \mathrm{~s}$ after a fight (Samarakone and Gonyou, 2009). The number and duration of fights, as well as latency to the first fight were recorded. The behavioral time values presented are the means and standard errors of the relative frequencies of each behavior, calculated from the results obtained from each observation of each group (Rhim, 2012).

To express the dominance and strength of the observed pigs, a dominance index (DI) was calculated. The DI was defined as the sum of wins minus defeats divided by the sum of wins, defeats, and stand-off outcomes (Stukenborg et al., 2011). The DI ranked from -1 (absolute submissive) to +1 (absolute dominant).

$$
\mathrm{DI}=\sum \frac{\text { wins }- \text { defeats }}{\text { wins }+ \text { defeat } s+\text { stand offs }}
$$

Data analysis was performed using the SAS software (SAS Inst. Cary, NY, USA) with the pen as the experimental unit. The residual data sets were tested for normal distribution using the Univariate Procedure of SAS. The data of aggressive behavior were not normally distributed and were transformed using the logarithm $\left(X^{\prime}=\right.$ $\left.\log _{10}[X+0.5]+0.5\right)$ to achieve normal distribution (Zar, 1999). The data were analyzed by analysis of variance (ANOVA). Tukey's post hoc tests were used to determine pair-wise differences between treatments. The Wilcoxon rank-sum test was used to identify significant differences in mean behavioral traits between dominant and submissive pigs after mixing at days 25, 50, and 75. A p values are presented.

\section{RESULTS}

Fight latency (ANOVA, $\mathrm{F}_{2,18}=18.9, \mathrm{p}=0.001$ ) was
Table 2. Fighting behavior of pigs after mixing at days 25,50 , and 75

\begin{tabular}{lccc}
\hline & Day 25 & Day 50 & Day 75 \\
\hline Fight latency (min) & 2.9 & 1.6 & 0.4 \\
Transformed data & $1.1^{\mathrm{a}}$ & $0.8^{\mathrm{b}}$ & $0.3^{\mathrm{c}}$ \\
Total duration of fighting (s/h) & 43.7 & 35.1 & $6.2^{\mathrm{a}}$ \\
Transformed data & $2.1^{\mathrm{a}}$ & $2.0^{\mathrm{a}}$ & $1.2^{\mathrm{c}}$ \\
Fighting frequency (no./h) & 3.2 & 1.5 & 0.3 \\
Transformed data & $1.0^{\mathrm{a}}$ & $0.8^{\mathrm{a}}$ & $0.4^{\mathrm{c}}$ \\
\hline
\end{tabular}

Different letters indicate significant differences between mean values on a given day (analysis of variance; $\mathrm{p}<0.05$ ).

significantly different among the age groups. Fight latency was significantly higher in the 25-day old group than the 75 -day old group (Tukey's test, $\mathrm{p}<0.05$ ). Total duration of fighting $\left(\mathrm{F}_{2,18}=7.4, \mathrm{p}=0.05\right)$ and fighting frequency $\left(\mathrm{F}_{2,18}\right.$ $=6.1, \mathrm{p}=0.05)$ were significantly lower in 75-day old group of pigs compared with the 25- and 50-day olds. There were no differences in total duration of fighting and fighting frequency between the 25- and 50-day old groups ( $p>0.05)$ (Table 2).

At day 25, more than three-fourths of the piglets had a DI between -0.2 and +0.2 . There were 7 absolutely dominant piglets $(\mathrm{DI}=+1)$ and 1 animal was absolutely submissive $(\mathrm{DI}=-1)$. The mean DI was 0.03 . At day 30 , thirty pigs had no winner outcomes $(\mathrm{DI}=-1)$ in contrast to no pig which was absolutely dominant. The other dominant animals had an index lower than 0.8. The mean DI for the growing pigs was -0.19 . At day 75 , forty percent of the pigs had a DI between -0.2 and +0.2 . There were 45 absolutely submissive pigs and 10 animals had a high index of 0.6. The mean DI of day 75 was 0.32 (Figure 1). Of the 360 pigs studied, 20 had no DI. These pigs either had no fights or the fight outcomes were uncertain.

A comparison of dominant (DI $>0)$ and submissive $(\mathrm{DI}<0)$ pigs showed significant differences $(\mathrm{p}<0.05)$ for major aggressive behaviors in all age groups (Table 3 ). Higher frequency and longer duration of aggressive interactions mean that dominant animals were more active than the submissive ones. Moreover, pigs with a positive DI initiated more fights $(\mathrm{p}<0.05)$.

\section{DISCUSSION}

In this study, we investigated the effect of mixing at

Table 3. Comparison of mean behavioral traits between dominant and submissive pigs after mixing at days 25,50 , and 75

\begin{tabular}{|c|c|c|c|c|c|c|}
\hline & \multicolumn{2}{|c|}{ Day 25} & \multicolumn{2}{|c|}{ Day 50} & \multicolumn{2}{|c|}{ Day 75} \\
\hline & $\mathrm{DI}<0$ & DI $>0$ & $\mathrm{DI}<0$ & DI $>0$ & $\mathrm{DI}<0$ & DI $>0$ \\
\hline Fights per pig (no./h) & $2.5^{\mathrm{b}}$ & $4.1^{\mathrm{a}}$ & $0.8^{\mathrm{b}}$ & $1.9^{\mathrm{a}}$ & $0.2^{\mathrm{b}}$ & $0.6^{\mathrm{a}}$ \\
\hline Fighting time per pig $(\mathrm{s} / \mathrm{h})$ & $21.4^{\mathrm{b}}$ & $53.9^{\mathrm{a}}$ & $18.2^{\mathrm{b}}$ & $45.6^{\mathrm{a}}$ & $2.8^{\mathrm{b}}$ & $10.3^{\mathrm{a}}$ \\
\hline Initiated fights per pig (no./h) & $13^{\mathrm{b}}$ & $21^{\mathrm{a}}$ & $8^{\mathrm{b}}$ & $15^{\mathrm{a}}$ & $3^{\mathrm{b}}$ & $7^{\mathrm{a}}$ \\
\hline
\end{tabular}

DI, dominance index.

Different letters indicate significant differences between mean values on a given day (Wilcoxon rank-sum test; $\mathrm{p}<0.05$ ). 


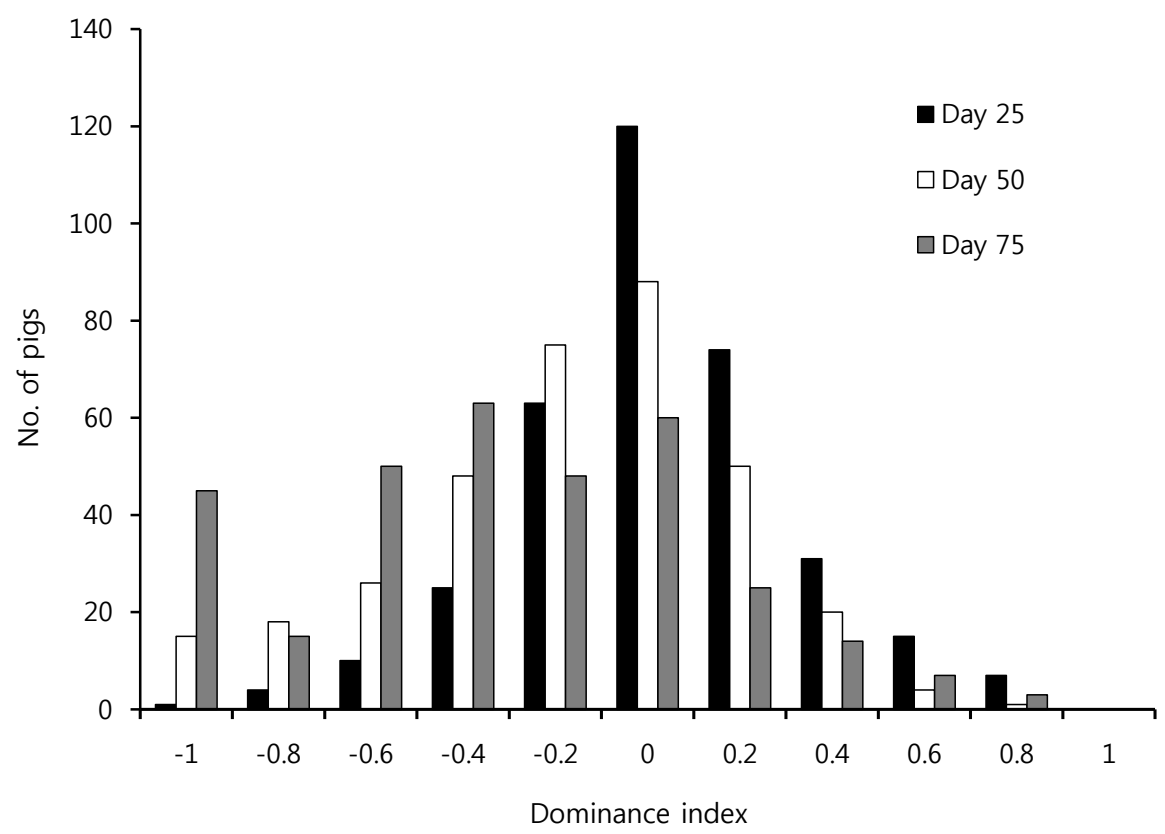

Figure 1. Dominance index of pigs after mixing at days 25, 50, and 75.

different days after weaning, on the aggressive behavior of pigs. All pigs used in this experiment were weaned at 25 $( \pm 1.2)$ days after birth. Moreover, they were post-mixed and subsequently as test pigs during each of two sessions during days 50 and 75. Animals were accustomed to the testing location, and the level of familiarity was the same for pigs derived from day 25 through day 75 .

In conventional swine production, piglets are usually mixed at weaning for efficient utilization of housing facilities (O’Connell et al., 2005). There was a high degree of aggressive behavior in piglets after the first mixing. Moreover, we found that the fight frequency, intensity, and duration, and the speed of group integration were affected by the level of aggressiveness of the individual pigs. Aggressive behavior occurs between pigs that are unfamiliar with each other (Meese and Ewbank, 1972; Arey and Edwards, 1998; Rhim, 2014).

The post-weaning mixing of piglets is a particularly stressful event and may be one of the major welfare concerns of the swine industry (Ewbank et al., 1974; Arey, 1999). When mixed after weaning, the piglets are influenced by the new piglets in pen, food, and separation from their mothers. These factors influence the aggressive behavior of piglets (D'Earth, 2005; Colson et al., 2006). Reduction of aggressive behavior may improve the welfare of piglets.

Our results show that older pigs have shorter fights after mixing and that they also sustain fewer injuries from these fights. A significant reduction in the expression of aggressive behavior by pigs at day 75 was apparent. Because mixing leads to higher levels of fighting (Parratt et al., 2006), there were more aggressive behaviors at day 25 .
A possible reason for the different level of aggressiveness may be the higher degree of familiarity of growing pigs compared to recently weaned piglets (Stukenborg et al., 2011). Moreover, aggressive behavior may be reduced because they learned from previous experience that there was no good result of fight.

The distribution of the DI and the mean value of approximately zero with regard to the DI from the pigs at days 25 and 50 indicate that there were uniform ratios between dominant and submissive pigs in the pen. However, after the third mixing, the mean value was -0.32 . This result means that most of the growing pigs had a negative DI. At day 75 , there were fewer highly dominant animals in each pen. Significant differences were shown in behavioral traits between the dominant and submissive animals $(\mathrm{DI}<0$ or $\mathrm{DI}>0$ ). These significant differences indicated that the pigs can be split into more or less active fractions using the DI, which is based on their aggressive behavior.

Post-mixing aggressive behavior changed over time. Early experience of mixing in the rearing conditions might contribute to reduced aggressive behavior of growing pigs (van de Weerd et al., 2005). It may have been occurred by more energetically efficiency strategy for stable social structure. This finding has potentially important consequences for animal welfare and economic production of commercial swine production.

\section{ACKNOWLEDGMENTS}

This study was supported by the Agriculture Science and Technology Project (Grant No: PJ009971) of the Rural Development Administration, Republic of Korea and the 
Chung-Ang University Graduate Research Scholarship Grants in 2015.

\section{REFERENCES}

Algers, B., P. Jensen, and L. Steinwall. 1990. Behaviour and weight changes at weaning and regrouping of pigs in relation to teat quality. Appl. Anim. Behav. Sci. 26:143-155.

Arey, D. S. 1999. Time course for the formation and disruption of social organization in group-housed sows. Appl. Anim. Behav. Sci. 62:199-207.

Arey, D. S. and S. A. Edwards. 1998. Factors influencing aggression between sows after mixing and the consequences for welfare and production. Livest. Prod. Sci. 56:61-70.

Ayo, J. O., S. B. Oladele, and A. Fayomi. 1998. Stress and its adverse effects on modern swine production. Pig News Inf. 19:51-56.

Borberg, C. and S. Hoy. 2009. Mixing of sows with or without the presence of a boar. Livest. Sci. 125:314-317.

Colson, V., P. Orgeur, V. Courboulay, S. Dantec, A. Foury, and P. Mormède. 2006. Grouping piglets by sex at weaning reduces aggressive behaviour. Appl. Anim. Behav. Sci. 97:152-171.

D'Earth, R. B. 2005. Socialising piglets before weaning improves social hierarchy formation when pigs are mixed post-weaning. Appl. Anim. Behav. Sci. 93:199-211.

Erhard, H. W., M. Mendl, and D. D. Ashley. 1997. Individual aggressiveness of pigs can be measured and used to reduce aggression after mixing. Appl. Anim. Behav. Sci. 54:137-151.

Estevez, I., I. L. Andersen, and E. Nævdal. 2007. Group size, density and social dynamics in farm animals. Appl. Anim. Behav. Sci. 103:185-204.

Ewbank, R. 1972. Social environment of the pig. In: Pig Production (Ed. J. A. Cole). University of Nottingham Press, Nottingham, UK. pp. 129-139.

Ewbank, R. and M. J. Bryant. 1972. Aggressive behaviour amongst groups of domesticated pigs kept at various stocking rates. Anim. Behav. 20:21-28.

Ewbank, R., G. B. Meese, and J. E. Cox. 1974. Individual recognition and the dominance hierarchy in the domesticated pig. the role of sight. Anim. Behav. 22:473-474.

Hillmann, E., F. von Hollen, B. Bunger, D. Todt, and L. Schrader. 2003. Farrowing conditions affect the reactions of piglets towards novel environment and social confrontation at weaning. Appl. Anim. Behav. Sci. 81:99-109.

Hoy, S. and J. Bauer. 2005. Dominance relationships between sows dependent on the time interval between separation and reunion. Appl. Anim. Behav. Sci. 90:21-30.

Krause, J. and G. D. Ruxton. 2002. Living in Groups. Oxford University Press, Oxford, UK.

Krauss, V. and S. Hoy. 2011. Dry sows in dynamic groups: An investigation of social behaviour when introducing new sows. Appl. Anim. Behav. Sci. 130:20-27.

Langbein, J. and B. Puppe. 2004. Analyzing dominance relationships by sociometric methods: a plea for a more standardized and precise approach in farm animals. Appl. Anim. Behav. Sci. 87:293-315.

Li, Y. and L. Wang. 2011. Effects of previous housing system on agonistic behaviors of growing pigs at mixing. Appl. Anim. Behav. Sci. 132:20-26.
McGlone, J. J. 1986. Influence of resources on pig aggression and dominance. Behav. Processes 12:135-144.

Meese, G. B. and R. Ewbank. 1972. A note on instability of the dominance hierarchy and variations in level of aggression within groups of fattening pigs. Anim. Prod. 14:359-362.

Meese, G. B. and R. Ewbank. 1973. The establishment and nature of the dominance hierarchy in the domesticated pig. Anim. Behav. 21:326-334.

Mendl, M., A. J. Zanella, and D. M. Broom. 1992. Physiological and reproductive correlates of behavioural strategies in female domestic pigs. Anim. Behav. 44:1107-1121.

National Research Council. 1996. Guide for the Care and Use of Laboratory Animals. National Academy Press, Washington DC, USA.

O'Connell, N. E. and V. E. Beattie. 1999. Influence of environmental enrichment on aggressive behavior and dominance relationships in growing pigs. Anim. Welf. 8:269279 .

O'Connell, N. E., V. E. Beattie, and D. Watt. 2005. Influence of regrouping strategy on performance, behaviour and carcass parameters in pigs. Livest. Prod. Sci. 97:107-115.

Parratt, C. A., K. J. Chapman, C. Turner, P. H. Jones, M. T. Mendl, and B. G. Miller. 2006. The fighting behaviour of piglets mixed before and after weaning in the presence or absence of a sow. Appl. Anim. Behav. Sci. 101:54-67.

Pitts, A. D., D. M. Weary, E. A. Pajor, and D. Fraser. 2000. Mixing at young ages reduces fighting in unacquainted domestic pigs. Appl. Anim. Behav. Sci. 68:191-197.

Rhim, S. J. 2012. Effects of group size on agonistic behaviors of commercially housed growing pigs. Rev. Colom. Cienc. Pecua. 25:353-359.

Rhim, S. J. 2014. Effects of floor space on the behavior of laying hens in commercial cages. Rev. Colom. Cienc. Pecua. 27:95101

Samarakone, T. S. and H. Y. Gonyou. 2009. Domestic pigs alter their social strategy in response to social group size. Appl. Anim. Behav. Sci. 12:8-15.

Schouten, W. G. P. 1991. Effects of rearing on subsequent performance in pigs. Pig News Inf. 12:245-247.

Statham, P., L. Green, M. Bichard, and M. Mendl. 2011. A longitudinal study of the effects of providing straw at different stages of life on tail-biting and other behaviour in commercially housed pigs. Appl. Anim. Behav. Sci. 134:100108

Stookey, J. M. and H. W. Gonyou. 1994. The effects of regrouping on behavioral and production parameters in finishing swine. J. Anim. Sci. 72:2804-2811.

Stukenborg, A., I. Traulsen, B. Puppe, U. Presuhn, and J. Krieter. 2011. Agonistic behaviour after mixing in pigs under commercial farm conditions. Appl. Anim. Behav. Sci. 129:2835 .

Turner, S. P., M. J. Farnworth, I. M. S. White, S. Brotherstone, M. Mendl, P. Knap, P. Penny, and A. B. Lawrence. 2006. The accumulation of skin lesions and their use as a predictor of individual aggressiveness in pigs. Appl. Anim. Behav. Sci. 96:245-259.

van de Weerd, H. A., C. M. Docking, J. E. L. Day, and S. A. Edwards. 2005. The development of harmful social behaviour in pigs with intact tails and different enrichment backgrounds 
in two housing systems. Anim. Sci. 80:289-298.

van Erp-van der Kooji, E., A. H. Kuijpers, J. W. Schrama, F. J. C.

M. van Eerdenburg, W. G. P. Schouten, and M. J. M. Tielen.

2002. Can we predict behaviour in pigs?: Searching for consistency in behaviour over time and across situations. Appl. Anim. Behav. Sci. 75:293-305.
Wechsler, B. and N. Brodmann. 1996. The synchronization of nursing bouts in group-housed sows. Appl. Anim. Behav. Sci. 47:191-199.

Zar, J. H. 1999. Biostatistical Analysis, 4th ed. Prentice-Hall Inc., Upper Saddler River, NJ, USA.

Zayan, R. and R. Dantzer. 1990. Social Stress in Farm Animal. Martinus Nijhoff, The Hague, The Netherlands. 